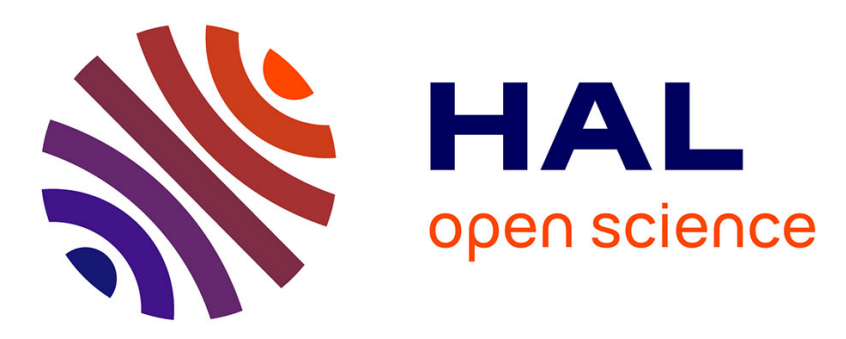

\title{
Nucleation of dislocations during nanoindentation in $\mathrm{MgO}$
}

Christophe Tromas, Yves Gaillard, Jacques Woirgard

\section{To cite this version:}

Christophe Tromas, Yves Gaillard, Jacques Woirgard. Nucleation of dislocations during nanoindentation in MgO. Philosophical Magazine, 2006, 86 (33-35), pp.5595-5606. 10.1080/14786430600690499 . hal-00513693

\section{HAL Id: hal-00513693 \\ https://hal.science/hal-00513693}

Submitted on 1 Sep 2010

HAL is a multi-disciplinary open access archive for the deposit and dissemination of scientific research documents, whether they are published or not. The documents may come from teaching and research institutions in France or abroad, or from public or private research centers.
L'archive ouverte pluridisciplinaire HAL, est destinée au dépôt et à la diffusion de documents scientifiques de niveau recherche, publiés ou non, émanant des établissements d'enseignement et de recherche français ou étrangers, des laboratoires publics ou privés. 


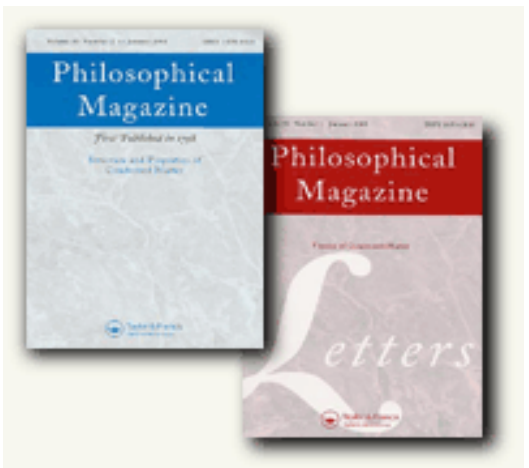

\section{Nucleation of dislocations during nanoindentation in $\mathbf{M g O}$}

\begin{tabular}{|c|c|}
\hline Journal: & Philosophical Magazine \& Philosophical Magazine Letters \\
\hline Manuscript ID: & TPHM-05-Nov-0522.R1 \\
\hline Journal Selection: & Philosophical Magazine \\
\hline $\begin{array}{r}\text { Date Submitted by the } \\
\text { Author: }\end{array}$ & 17-Feb-2006 \\
\hline Complete List of Authors: & $\begin{array}{l}\text { Tromas, Christophe; Universite de Poitiers, Laboratoire de } \\
\text { metallurgie physique } \\
\text { gaillard, yves; UPC, CMEM } \\
\text { Woirgard, Jacques; CNRS, laboratoire de metallurgie physique }\end{array}$ \\
\hline Keywords: & $\begin{array}{l}\text { plastic deformation, dislocations, nucleation, plasticity, } \\
\text { nanoindentation }\end{array}$ \\
\hline Keywords (user supplied): & pop-in \\
\hline
\end{tabular}

\section{S ScholaroNE \\ Manuscript Central}




\title{
Nucleation of dislocations during nanoindentation in $\mathrm{MgO}$
}

Keywords: nanoindentation, plasticity, homogeneous nucleation, dislocation, pop-in.

\begin{abstract}
$\underline{\text { Abstract: }}$
This study investigates the incipient plasticity during a nanoindentation test with a spherical indenter in magnesium oxide single crystals. The load displacement curves show multiple pop-ins, interspaced by elastic deformation, and making the transition from an initial elastic deformation regime to a continuous elasto-plastic one. Nanoindentations have been stopped after the first pop-in and the dislocation structures have been three dimensionnally characterised by AFM observations of the surface deformation and by nanoetching. The dislocation pattern shows two activated slip systems, The resolved shear stress has been calculated just before the pop-in, for all of the activated slip systems. The final positions of the dislocations generated during the first pop-in reveal that they were all nucleated at the point of maximum resolved shear stress.
\end{abstract}

Deleted: fully

Deleted: se structures are limited to two dislocation pile ups in two different slip systems 


\section{Introduction}

The nanoindentation test, though originally developed for the determination of local mechanical properties, provides a new interesting tool to study the early stages of plasticity. In many materials, incipient plasticity during nanoindentation is characterized by an initial displacement burst called pop-in. Pop-ins have been observed in ceramics [1-3], semiconductors [4-5] or metals [6-8]. Gerberich and co-workers have ascribed pop-in phenomenon in passivated metal surfaces to oxide layer breakage $[4,9]$. In plastic crystalline materials, this yielding, which makes the elastic-plastic transition, is commonly associated to the homogeneous nucleation of dislocations [5,6-7]. This assumption is supported by the very high stress that can be reached, due to the nanometre scale contact area between the indenter and the material, in regions of materials small enough to be defect free. The hypothesis of homogeneous nucleation of dislocations during nanoindentation has been corroborated during the last few years by several atomistic calculations in metals [10-12]. However, there is still a lack in experimental data's on the real nucleation process. In particular, the experimental knowledge of the exact nucleation site of the dislocations and of the specific slip systems activated during the pop-in is of great interest for a better understanding of incipient plasticity during nanoindentation.

In this work, nanoindentations have been performed on a (001) surface of magnesium oxide $(\mathrm{MgO})$ single crystals. $\mathrm{MgO}$ is a fcc material with rather simple plasticity, as there are only six kinds of slip systems instead of twelve for a classical fcc crystal. These systems can be divided into two groups: four $<110>\{110\}_{45}$ slip systems, with slip planes inclined at $45^{\circ}$ form the surface $(001)$ and two $<110>\{110\}_{90}$ slip systems with slip planes perpendicular to the (001) surface. These specific slip systems give rise to surface deformations around an 
indent organised as a rosette arms pattern [13-15]. In this study, a spherical indenter with a large radius of curvature $(10 \mu \mathrm{m})$ was used rather than a Berkovich one with the purpose of producing a less concentrated dislocation structure, for an easier identification. Furthermore, the expression of the stress field under an elastic sphere-plane contact (Hertz contact) is well known $[16,17]$. It allowed the calculation of the resolved shear stress just before the initial stage of plasticity. In the case of the spherical indenter, multiple pop-ins are observed on the loading curves. The dislocation structures generated during the first pop-in have been determined through the observation of the slip line pattern on the surface by atomic force microscopy, and by the nanoetching technique. These structures have been found to be very simple as they are limited, just after the first pop-in, to one or few dislocation pile ups. The activated slip systems have been fully characterized and the stress field at the beginning of the first pop-in has been calculated. The results show unambiguously that the dislocations generated during the first pop-in are all nucleated at the point of maximum resolved shear stress in their respective slip system.

\section{Experiments}

Nanoindentations have been performed on a freshly cleaved (001) surface of $\mathrm{MgO}$, with a NHT apparatus from CSM Instruments. This apparatus was equipped with a diamond spherical indenter with a $10 \mu \mathrm{m}$ radius of curvature. This radius has been determined by indenting a fused silica sample of known Young's modulus ( $72 \mathrm{GPa}$ ), and controlled by direct observation by AFM. The resulting surface deformations were observed by AFM. The nanoetching technique [18] was also used to investigate the dislocation structure in the volume. This technique consists in revealing the emergence points of dislocations by chemical etching. The etching sequence is repeated after removing thin layers of material by chemo- 
mechanical polishing (CMP). The nanometre size etch pits are observed by atomic force microscopy. This sort of tomography of dislocations allows identifying the 3D organization of individual dislocations around a nanoindentation imprint [15,18]. AFM observations were performed in tapping mode on a D3100 apparatus from Digital Instruments.

\section{Results and discussion}

\subsection{Nanoindentation curves}

When indenting $\mathrm{MgO}$ single crystals with a Berkovich indenter, a pop-in is always observed [3]. The deformation is purely elastic before the pop-in and elasto-plastic after the pop-in [19]. The critical load for the pop-in is different from one indentation to another, and ranges from $0.4 \mathrm{mN}$ to $2.8 \mathrm{mN}$ with the Berkovich indenter. However, as observed on figure $1 \mathrm{a}$ where different nanoindentation curves obtained with a Berkovich indenter have been superimposed, the pop-in always makes the transition from an elastic deformation curve to a master curve representative of the elasto-plastic deformation regime. The tip of the Berkovich indenter used in this study is fairly blunt, and can be approximated by a $360 \mathrm{~nm}$ radius sphere, as confirmed by the Hertzian fit performed on the elastic part of the curves in figure 1a.

With the $10 \mu \mathrm{m}$ spherical indenter, multiple pop-ins are observed as shown on figure $1 \mathrm{~b}$. As for the Berkovich indenter, when the nanoindentation is stopped before the first pop-in, the force-penetration curve does not show any hysteresis, demonstrating thus that the deformation is purely elastic before the first pop-in. The deformation after the last pop-in is also described by the master curve of the elasto-plastic regime. With this spherical indenter, the first pop-in occurs at variable loads, ranging form $8 \mathrm{mN}$ to $30 \mathrm{mN}$. However, during the first pop-in, the penetration depth is several orders of magnitude lower than the radius of the indenter. This point ensures that the elastic contact before the pop-in can be described as a Hertzian contact. In figure $1 b$, the elastic deformation curve, as calculated from the Hertz formulation [17], has 
been plotted in dashed line. The master curve of the elasto plastic regime, also plotted in dashed line, has been deduced from nanoindentations where the pop-ins occurred at very low loads. The multiple pop-ins, whatever being their apparition loads, make the transition from the elastic curve to the continuous elasto-plastic one. Nanoindentation curves stopped after one or several pop-ins have shown that the deformation between two successive pop-ins remains purely elastic. So, with the $10 \mu \mathrm{m}$ spherical indenter, the transition from the elastic deformation to a continuous elasto-plastic regime is ensured by successive plastic displacement bursts interspaced by elastic loadings.

\subsection{Dislocation structures}

Nanoindentations stopped before the continuous elasto-plastic regime, that is after the first or second pop-in for example, exhibit surface deformations limited to few slip lines, without real indentation imprint reproducing the indenter shape. In particular, when the indentation is stopped after the first pop-in, a single slip line is generally observed, as shown on the indentation A on figure 2a, with a very small cavity on one side of the slip line. This slip line is oriented along a [010] direction and corresponds, according to the slip systems of $\mathrm{MgO}$, to dislocations lying in a $\{110\}_{45}$ plane. The step height of $6.4 \mathrm{~nm}$ measured by AFM indicates that the slip lines corresponds to the emergence of 30 dislocation half loops. This structure, though very simple compared to those observed around classical Berkovich nanoindentations in $\mathrm{MgO}$, recalls the rosette arms pattern because of the slip line orientation. Cleavage steps are also observed on the surface. A first chemical etching on the indented surface presented on figure $2 \mathrm{~b}$ shows that two slip systems are actually activated around the observed indent: the $<110>\{110\}_{45}$ slip systems corresponding to the previously observed slip line, and a $<110>\{110\}_{90}$ slip system, revealed by the etch pits alignment along the $[1 \overline{10}]$ direction. 
dislocations with a Burgers vector parallel to the surface. According to previous study on the dislocation structures around nanoindentation in $\mathrm{MgO}_{[}[15,18]$, this last system, which accommodates the lateral deformation, is composed of two sets of dislocation half loops of opposite Burgers vectors depending on their position with respect to the indentation axis. This etching pattern also differentiates unambiguously the cleavage steps from the slip lines as no etch pits are produced along the cleavage steps. The figure $2 \mathrm{c}$ presents a second chemical etching pattern obtained around the same indent A after removing a $200 \mathrm{~nm}$ thick layer of material by CMP. As expected, the etch pits alignment along the $[\overline{1} 10]$ direction is nearly the same as that observed on the initial surface. It corresponds indeed to dislocation perpendicular to the surface, so the etch pits are all at the same place as on the surface etching pattern. However, the etch pits alignment along the [100] direction has moved $200 \mathrm{~nm}$ toward the indentation axis. This clearly proves that the corresponding dislocations are all in a convergent $(10 \overline{1})_{45}$ plane, that is a plane lying below the indented area [18]. This dislocation structure is schematized on figure 3.

\subsection{Resolved shear stress}

A common assumption made for the interpretation of experiments about incipient plasticity during nanoindentation, is that nucleation of dislocations is supposed to occur where the principal shear stress reaches a value close to the theoretical strength. This consideration does not take into account the slip planes that are really activated. A more realistic approach, in the case of a single crystal, is to make the hypothesis that the pop-in corresponds to the nucleation of dislocations at the point of maximum resolved shear stress (RSS). In the previous part, it has been shown that the dislocation structure around the nanoindentation A (stopped after the

Deleted: homogeneous Deleted: homogeneous 

planes. In the following, the RSS will be calculated for both of these systems

The deformation before the pop-in is fully elastic. So, as a spherical indenter was used, all the stress tensor components $\sigma_{\mathrm{ij}}$ can be calculated in the material before the pop-in. In particular, the contact radius $\mathrm{a}_{\mathrm{c}}$ just before the pop-in is given by the formula [17]:

$$
a_{c}=\left(\frac{3 F R}{4 E^{*}}\right)^{1 / 3}
$$

with $\mathrm{F}$ the applied load, $\mathrm{R}$ the spherical indenter radius $(10 \mu \mathrm{m})$ and $\mathrm{E}^{*}$ the reduced Young's modulus defined by:

$$
\frac{1}{\mathrm{E}^{*}}=\frac{1-v_{\mathrm{ind}}^{2}}{\mathrm{E}_{\mathrm{ind}}}+\frac{1-v_{\mathrm{MgO}_{\mathrm{g}}}^{2}}{\mathrm{E}_{\mathrm{MgO}}}
$$

Formatted: English (U.K.), Lowered by $16 \mathrm{pt}$

Formatted: Centered

Formatted: Subscript Formatted: Subscript $\mathrm{nm}$. A new formulation for the stress field under a Hertzian contact has been recently proposed by Hanson et al. [20]. This formulation, which leads to an easier numerical calculation, has been used in this study. In the following, the stress induced by the indenter is calculated in Cartesian coordinates, with the origin at the intersection between the surface and the indentation axis, and the following axis orientation: x'x along [100], y'y along [010] and z'z along [001]. The RSS acting on a $<110>\{110\}_{45}$ slip system is $\frac{1}{2}\left(\sigma_{z z}-\sigma_{x x}\right)$ for slip planes emerging along a [010] surface direction, and $\frac{1}{2}\left(\sigma_{z z}-\sigma_{y y}\right)$ for slip planes emerging along a [100] surface direction. This RSS have been calculated for the $[101](10 \overline{1})_{45}$ slip 
system observed around the nanoindentation A and is plotted on figure 4a. A maximum is observed along the indentation axis at a depth of $0.44 \mathrm{a}_{\mathrm{c}}$, with $\mathrm{a}_{\mathrm{c}}$ the radius of the contact area. For the indentation $\mathrm{A}$, this maximum just before the pop-in is $4.1 \mathrm{GPa}$ and is located at a depth of $328 \mathrm{~nm}$. Let's make the hypothesis that under such a high stress, glissile dislocation loops are homogenously nucleated in the $(10 \overline{1})_{45}$ plane on the indentation axis. These loops then extend until they reach the surface, where they produce a slip line, As they glide along a slip plane inclined at forty five degrees from the surface, the knowledge of the nucleation site allows to predict the formation of this slip line at a distance of $0.44 \mathrm{a}_{\mathrm{c}}$ from the indentation axis. In the case of the nanoindentation $\mathrm{A}$, the slip line is predicted to appear $328 \mathrm{~nm}$ from the indentation axis, This slip line and the contact circle are schematized on figure 5a.

For the $<110>\{110\}_{90}$ slip systems, the RSS is $\frac{1}{2}\left(\sigma_{x x}-\sigma_{y y}\right)$ or $\frac{1}{2}\left(\sigma_{y y}-\sigma_{x x}\right)$ according to the system considered. This RSS has been calculated for the $<110>\{110\}_{90}$ slip systems observed on the nanoindentation A, and is plotted on figure $4 \mathrm{~b}$. This RSS presents four identical maxima at a depth of $0.65 \mathrm{a}_{c}$, a radial distance of $1.1 \mathrm{a}_{\mathrm{c}}$ from the indentation axis and angular positions relative to the [100] direction: $\theta=0, \theta=\pi / 2, \theta=\pi$, and $\theta=3 \pi / 2$. The projections of these four sites on the surface are indicated by numbers 1 to 4 on figure $5 \mathrm{a}$. In the case of the indentation A, just before the pop-in, this RSS maximum is $431 \mathrm{MPa}$, and is located at a depth of $477 \mathrm{~nm}$, and at a distance of $818 \mathrm{~nm}$ from the indentation axis. Let's consider, in the case of the nanoindentation $\mathrm{A}$, the nucleation of dislocation loops in the (110 $)_{90}$ slip plane at two of these points of maximum RSS. These loops extend in their slip planes until reaching the surface. The emergence points of these dislocations are predicted to be aligned along the $[1 \overline{1} 0]$ directions containing the surface projection of the nucleation site. Such dislocation emergence points alignments are schematized by dotted lines on figure $5 \mathrm{a}$, in the case of dislocations nucleated at sites 1 and 2 . In the figure $5 \mathrm{~b}$, the predictive scheme of the
Deleted: reaching the surface and producing a slip line

Deleted: The position of the

Deleted: and the $(101)_{45}$ slip plane

Deleted: , that is at

Deleted: in the case

Deleted: of the nanoindentation A
Deleted: Two of these possible point alignments, associated to the nucleation Deleted:

Deleted: , are schematized on figure $5 \mathrm{a}$ by dotted lines 
dislocation structure nucleated during the first pop-in, based on the positions of the RSS maxima, has been superimposed to the AFM image the surface etching pattern around nanoindentation $\mathrm{A}$, at the same scale (same image as in figure $2 \mathrm{~b}$ ). The scheme fits perfectly with the observed dislocation structures.

A closer study of the etch pits alignments around the nucleation site 1, indicated by an arrow on figure $5 b$, have been carried out. A higher magnification of this alignment on figure $5 b$ shows that the etch pits are distributed by pairs on either side of the projection of the nucleation site. This is consistent with the hypothesis of dislocation loops that extend on either side of this nucleation site. These dislocation loops have been schematized on the magnification of figure $5 \mathrm{~b}$. Furthermore, an elastic calculation of the dislocation positions in this pile up after removing the indenter gave the same distribution as that observed experimentally $\lfloor 21]$. These results validate the initial hypothesis of dislocation nucleation at the point of maximum RSS. Furthermore, these results have been found to be reproducible with other nanoindentations stopped after the first pop-in.

For the second set of dislocations of the activated $<110>\{110\}_{90}$ slip systems, even if the position of the etch pits line is in good agreement with the predicted nucleation site 2 , one may argue that dislocations are not distributed in pairs because the etch pits are all on the same side of the nucleation site 2. However, in this case, these dislocations may have moved toward the dislocations lying in the $(10 \overline{1})_{45}$ slip plane to interact according to the dislocation reaction in $\mathrm{MgO}$ :

$$
\frac{1}{2}[\overline{1} 10]+\frac{1}{2}[101] \rightarrow \frac{1}{2}[011]
$$

This reaction, which has been widely observed around nanoindentations in $\mathrm{MgO}$, results in a sessile dislocation segment oriented along the $[11 \overline{1}]$ direction. This assumption is reinforced by the four etch pits of the $[1 \overline{1} 0](110)_{90}$ slip system that are grouped together close to the
Deleted: This

Deleted: homogeneous 
$[101](10 \overline{1})_{45}$ activated slip system. Finally, the position of this second set of dislocations in the $(110)_{90}$ corroborates the assumption of a nucleation at the site 2 , and the hypothesis of nucleation at the point of maximum resolved shear stress.

\subsection{About a nucleation criterion}

The results presented in this article do not provide a specific criterion for dislocation nucleation. They only prove that the dislocation nucleation, associated to the pop-in phenomenon, occurs at the point of maximum resolved shear stress for the considered slip system. They also cannot explain why the pop-in load is different from one indentation to another. However, this last point must be put into perspective, with reference to the previous results. The resolved shear stress seems to be a more accurate parameter than the pop-in load to study the dislocation nucleation during a nanoindentation test. The maximum RSS is found

Deleted: In the previous part, the sites of nucleation of dislocations have been unambiguously determined. However, these results do not provide a specific criterion for dislocation nucleation.

Deleted: resolved shear stress to be $0.5 \mathrm{P}_{\mathrm{m}}$ for the $<110>\{110\}_{45}$ slip systems and $0.05 \mathrm{P}_{\mathrm{m}}$ for the $<110>\{110\}_{90}$ slip systems, with $\mathrm{P}_{\mathrm{m}}$ the mean contact pressure:

$$
\mathrm{P}_{\mathrm{m}}=\frac{2}{3}\left(\frac{6 \mathrm{FE} *^{2}}{\pi^{3} \mathrm{R}^{3}}\right)^{1 / 3}
$$

with $\mathrm{F}$ the applied load, $\mathrm{E}^{*}$ the reduced Young's modulus, and $\mathrm{R}$ the radius of the spherical indenter. So, the maximum of the RSS varies rather slowly, as the cube root of the applied load. This can explain, if the nucleation of dislocation is a thermally activated phenomenon, why the pop-in load can occurs in such a large range. Finally, it is also surprising that the $<110>\{110\}_{45}$ slip system is activated at the same time as the $<110>\{110\}_{90}$ slip system, because for a given load, the maximum of the RSS is ten times lower for the last one. However, as observed for the nanoindentation A, there are only about ten dislocations in this last system, compared to thirty in the $\leq 110 \geq\{110\}_{45}$ slip system. For some other indentations also stopped after the pop-in, no dislocations were found in the $<110>\{110\}_{90}$ slip system. 


\section{Conclusion}

For nanoindentations performed on (001) $\mathrm{MgO}$ surface with a spherical indenter of $10 \mu \mathrm{m}$ of radius of curvature, the incipient plasticity is characterised on the load-displacement curves by a staircase yielding. These successive pop-ins, interspaced by elastic loading sequences, make the transition from an initial elastic deformation regime to a continuous elasto-plastic one. Nanoindentations have been stopped after the first pop-in, and the dislocation structures have been characterized by AFM observation of the surface deformation and by using the nanoetching technique. Contrary to classical Berkovich nanoindentations, these dislocation structures are limited to very few dislocation pile ups, allowing an individual identification of each of them. The resolved shear stress of the corresponding slip systems have been then calculated just before the first pop-in, that is, when the deformation is still elastic. The final positions of the dislocations clearly demonstrate that they have been nucleated where the RSS is maximum in each of the activated slip planes. This work does not pretend to explain what is the mechanism of nucleation of dislocations, but it shows unambiguously that incipient plasticity during nanoindentation in $\mathrm{MgO}$ is due to nucleation of dislocations in the volume, and clearly identify the nucleation site as the point of maximum resolved shear stress. These results give a new insight about the incipient plasticity process, which are difficult to characterize experimentally. They may be of great interest for further atomistic simulations of dislocation nucleation during nanoindentation.

Deleted: homogeneous

Deleted: homogeneous 


\section{References}

[1] T.F. Page, W.C. Oliver, C.J. McHargue, J. Mater. Res. 7450 (1992).

[2] N.I. Tymiak, A. Daugela, T.J. Wyrobek, O.L. Warren, Acta Mat. 52553 (2004).

[3] Y. Gaillard, C. Tromas, J. Woirgard, Phil. Mag. Lett. 83553 (2003).

[4] W.W. Gerberich, J.C. Nelson, E.T. Lilleoden, P. Anderson, J.T. Wyrobek, Acta Mater. 44 $\underline{3585(1996) .}$

[5] D. Lorenz, A. Zecker, U. Hilpert, P. Grau, H. Johansen, H.S. Leipner, Phys. Rev. B 67 $172101(2003)$.

[6] D.F. Bahr, D.E. Kramer, W.W. Gerberich Acta Mater. 463605 (1998).

[7] Y.L. Chiu, A.H.W. Ngan, Acta Mat. 502677 (2002).

[8] C.A. Schuh, J.K. Mason, C. Lund, Nature Materials 4617 (2005). Formatted: Spanish (Spain-Modern Sort)

[9] W.W. Gerberich, S.K. Venkataraman, H. Huang, S.E. Harvey, D.L. Kohlstedt, Acta Metall. Mater. 431569 (1995).

[10] J. Li, K.J. Van-vliet, T. Zhu, S. Yip, S. Suresh, Nature 418307 (2002).

[11] E.T. Lilleodden, J.A. Zimmerman, S.M. Foiles, W.D. Nix, J. Mech. Phys. Solids 51901 (2003).

[12] C.L. Kelchner, S.J. Plimpton, J.C. Hamilton, Phys. Rev. B 58,11085 (1998).

[13] A.S. Keh, J. Appl. Phys. 311538 (1960).

[14] R.W. Armstrong, C. CM.WU, J. Amer. Ceram. Soc. 61102 (1978).

[15] C. Tromas, Y. Gaillard, Encyclopedia of Materials: Science and Technology (Elsevier Science Ltd, 2004), pp. 1-4.

[16] M.T. Huber, Ann. Phys. 43153 (1904)

Deleted: I

[1] W.W. Gerberich, S.K. Venkataraman, H. Huang, S.E. Harvey, D.L. Kohlstedt, Acta Metall. Mater. 431569 (1995).II [2] W.W. Gerberich, J.C. Nelson, E.T. Lilleoden, P. Anderson, J.T. Wyrobek, Acta Mater. 443585 (1996). II

[3] Y. Gaillard, C. Tromas, J. Woirgard, Phil. Mag. Lett. 83553 (2003). II

[4] Y.L. Chiu, A.H.W. Ngan, Acta Mat. 502677 (2002). II

[5] D.F. Bahr, D.E. Kramer, W.W

Gerberich Acta Mater. 463605 (1998).II [6] D. Lorenz, A. Zecker, U. Hilpert, P. Grau, H. Johansen, H.S. Leipner, Phys. Rev. B 67172101 (2003).II

[7] T.F. Page, W.C. Oliver, C.J. McHargue, J. Mater. Res. 7450 (1992).II

[8] N.I. Tymiak, A. Daugela, T.J.

Wyrobek, O.L. Warren, Acta Mat. 52553 (2004).II

[9] C.A. Schuh, J.K. Mason, C. Lund, Nature Materials 4617 (2005).II

Formatted: German (Germany)

Formatted: Spanish (Spain-Modern Sort)

Deleted: 70

Deleted: 100102

Deleted: 2004 
[17] K.L. Johnson, Contact mechanics (Cambridge university press, 1985).

[18] Y. Gaillard, C. Tromas, J. Woirgard, Acta Mater. 511059 (2003).

[19] C. Tromas, J.C. Girard, V. Audurier, J. Woirgard, J. Mater Sci. 345337 (1999).

[20] M.T. Hanson, T. Johnson, J. Trib. 115327 (1993).

[21] Y. Gaillard, C. Tromas, J. Woirgard, Acta Mater. 541409 (2006).

Formatted: English (U.K.)

Formatted: Font: Bold

Formatted: English (U.K.) 


\section{Figure captions:}

Figure 1: (a) superposition of several nanoindentation curves performed with a Berkovich indenter in $\mathrm{MgO}$; (b) nanoindentation curve in $\mathrm{MgO}$ with a spherical indenter. For clarity, the unloading curve is not represented.

Figure 2: Nanoindentation A, stopped after the first pop-in: (a) AFM image of the surface deformation; (b) Chemical etching pattern on the indented surface; (c) chemical etching pattern after removing a $200 \mathrm{~nm}$ thick layer of material

Figure 3: Schematic of the 3D dislocation structure around the nanoindentation A.

Figure 4: (a) Resolved shear stress for the $<110>\{110\}_{45}$ slip system and (b) for the $<110>\{110\}_{90}$ slip system, represented in the (100) plane containing the indentation axis. The nucleation of a glissile dislocation loop is schematized on figure (a).

Figure 5: (a) Schematic of the site of maximum resolved shear stresses projected on the surface. The predicted position of the slip line and of the etch pits alignments relative to the indentation axis are also indicated. (b) Superposition of the previous schematic to the surface nanoetching pattern (see figure $2 b$ ), at the same scale. A magnification of the [110] etch pits alignments emphasizes the etch pits position with respect to the supposed nucleation site. 

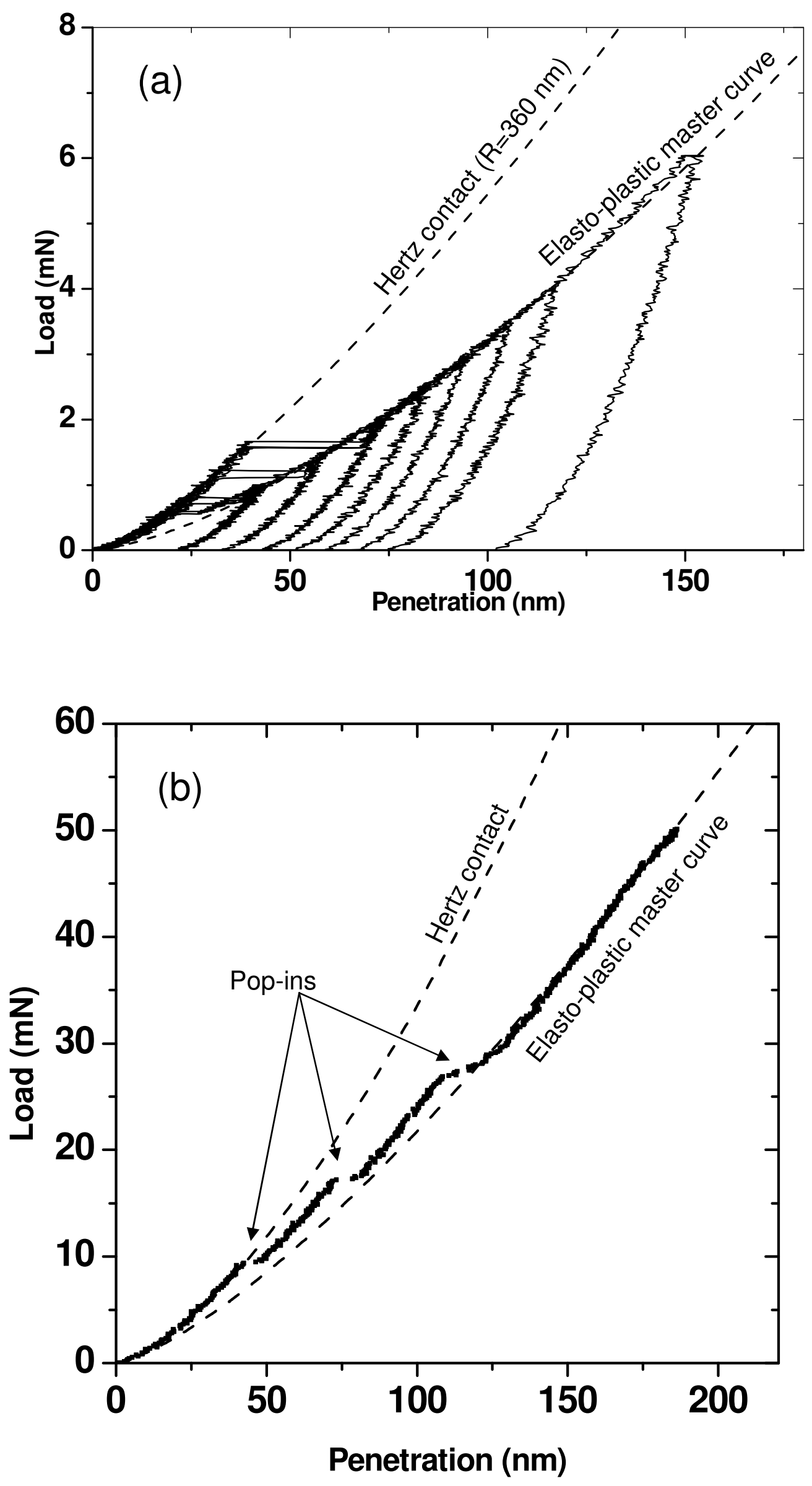

http://mc.man[Figig|utrerat.com/pm-pml 

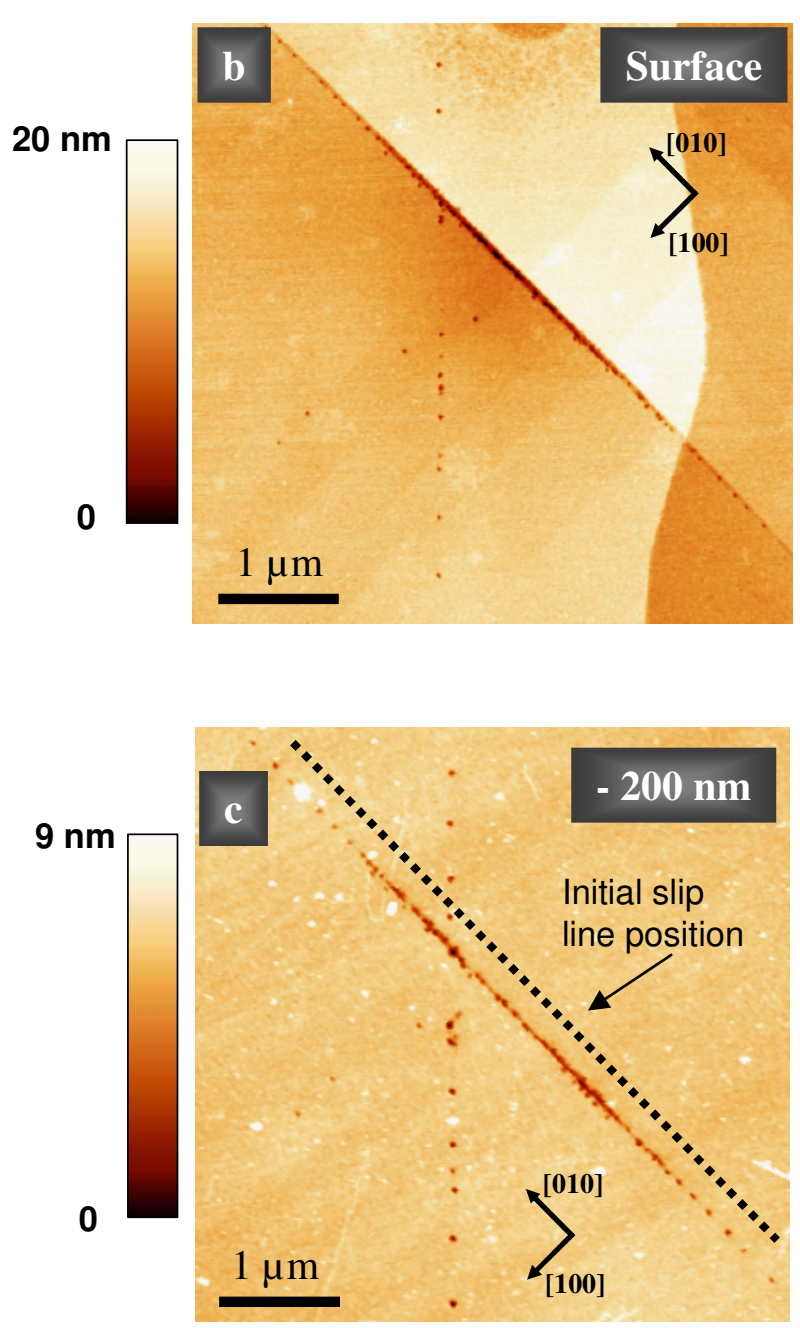

Figure 2

http://mc.manuscriptcentral.com/pm-pml 


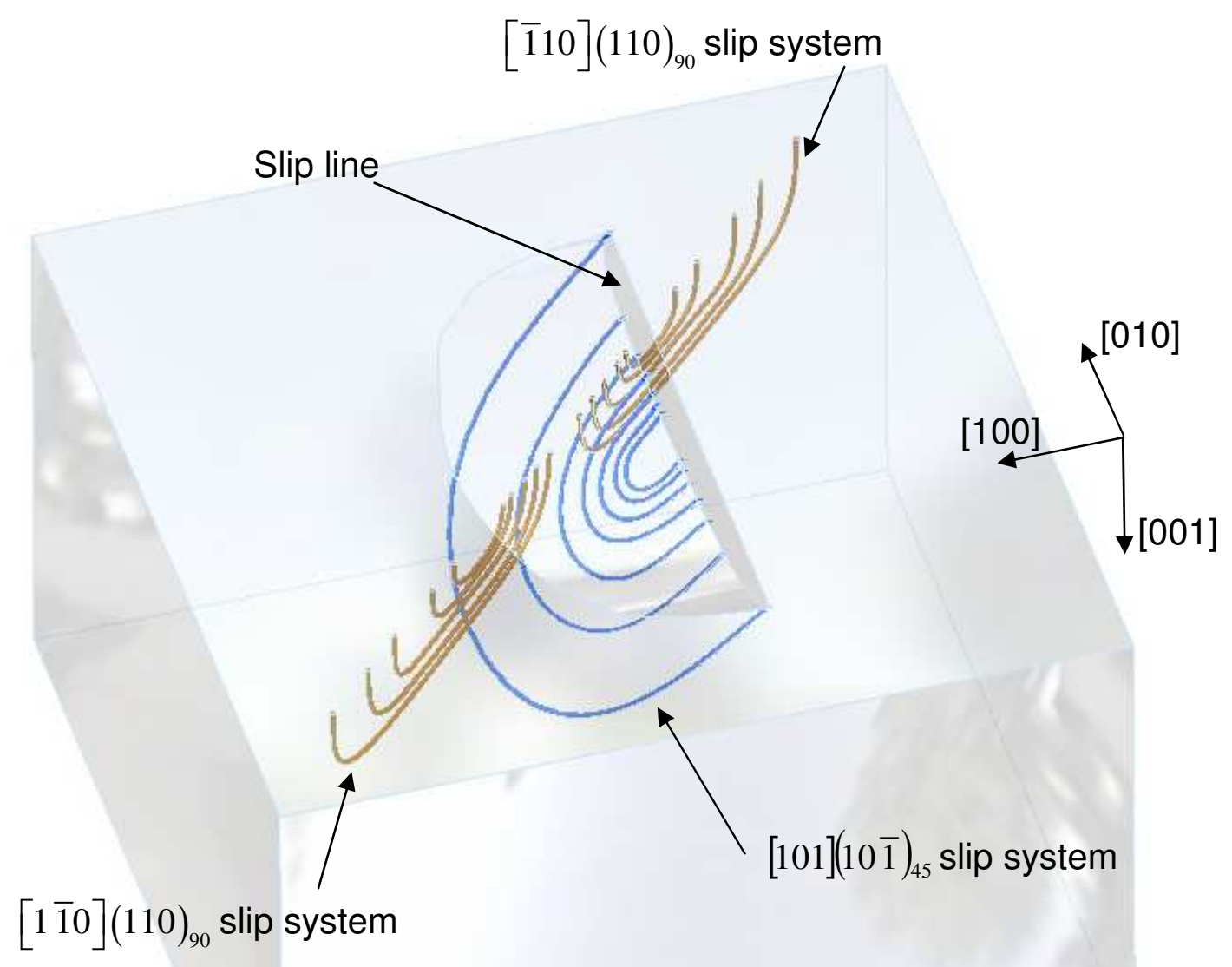

Figure 3

http://mc.manuscriptcentral.com/pm-pml 


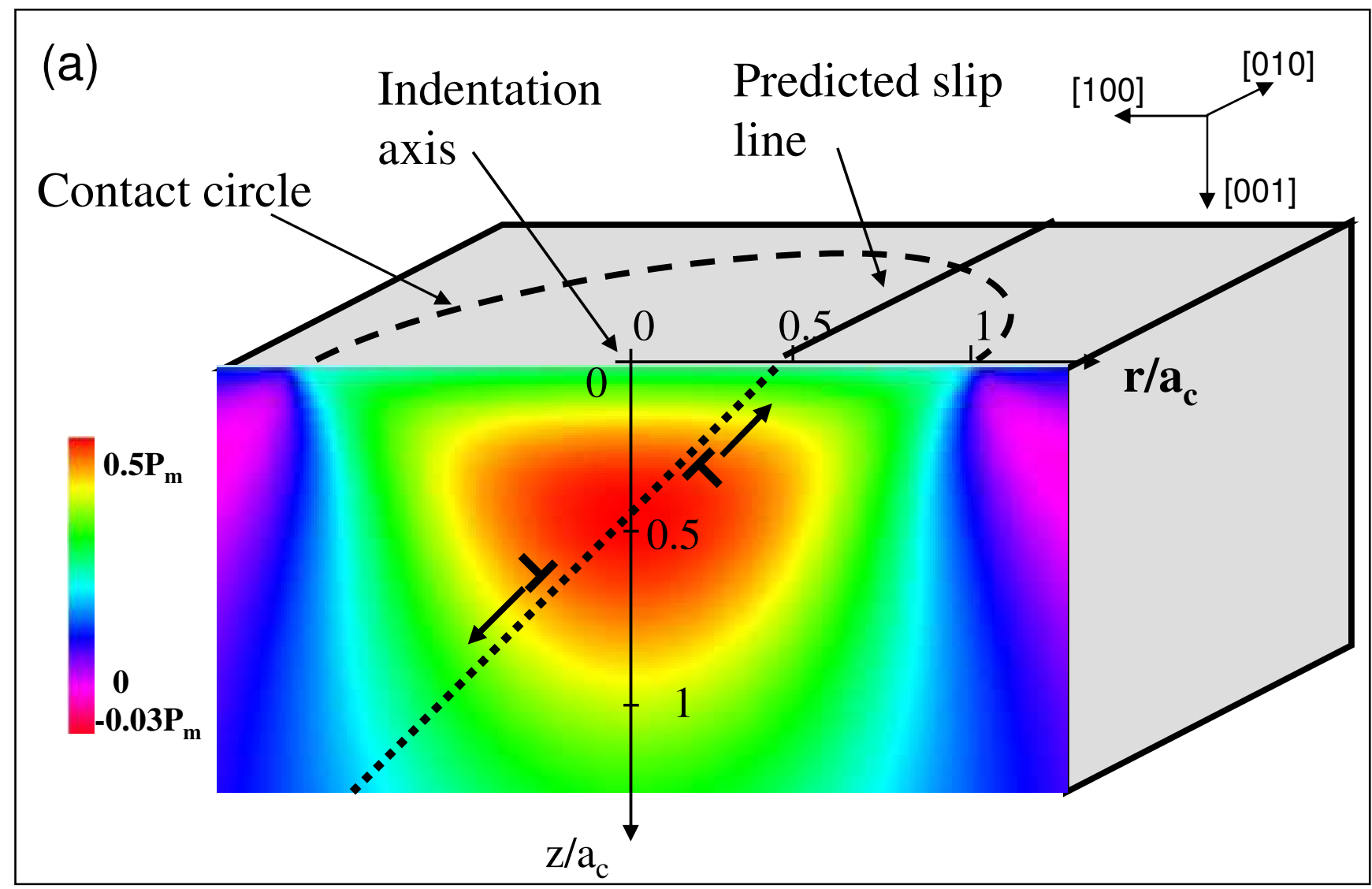

(b)

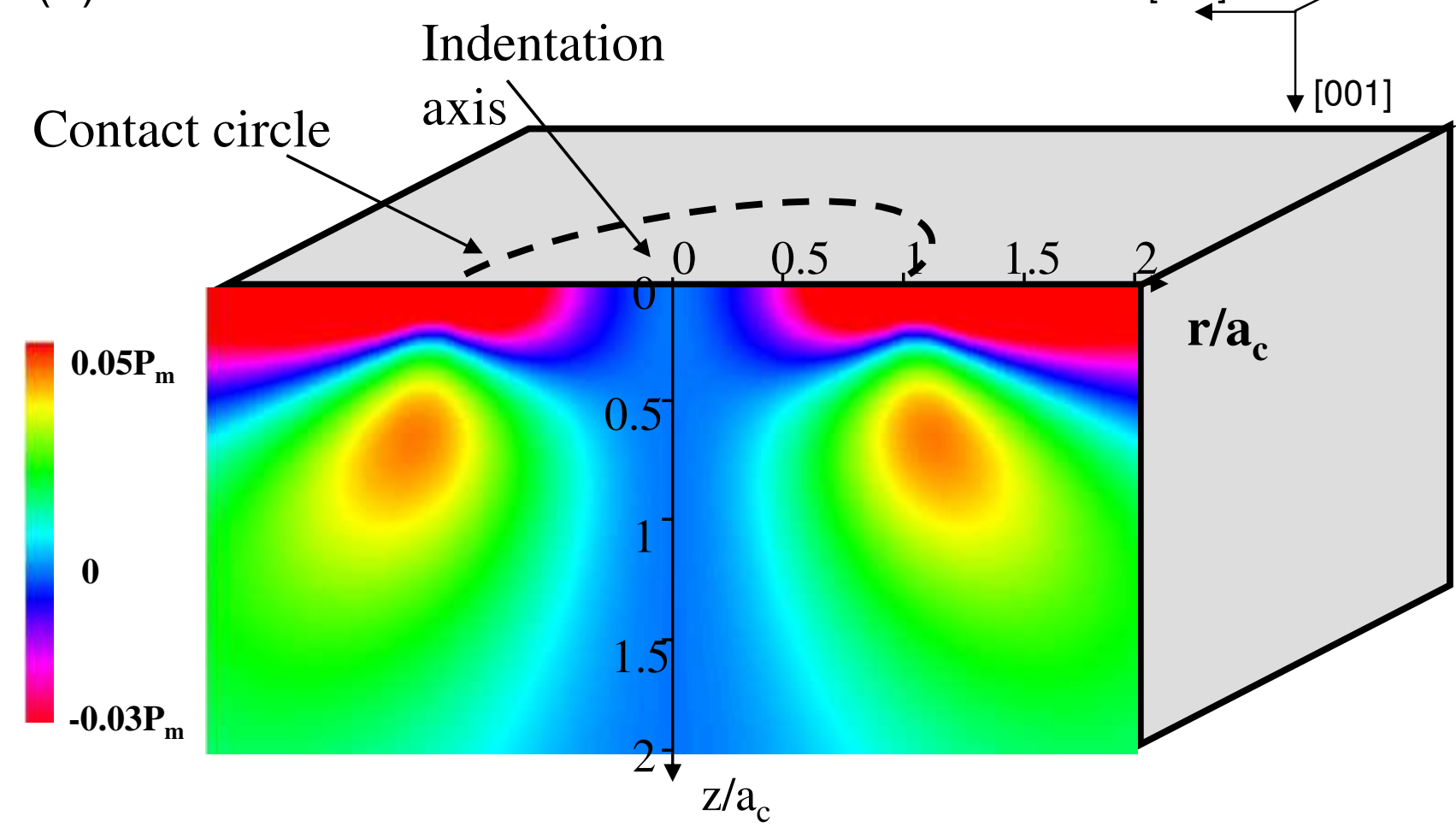

Figure 4 

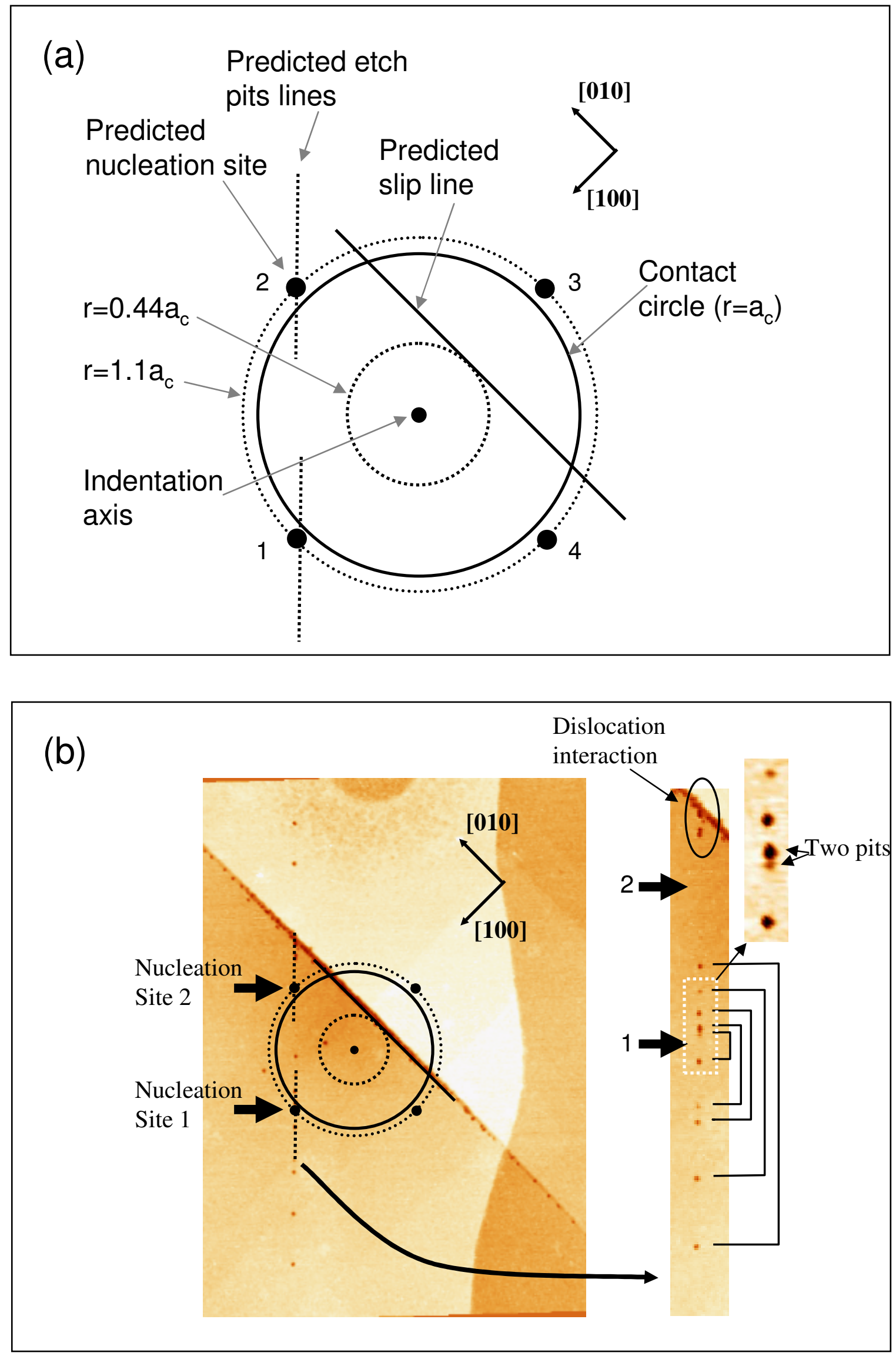

Figure 5 